Please quote as: Riedl, C.; Leimeister, J. M. \& Krcmar, H. (2010): Service innovation for electronic services. In: Service Delivery Platforms: Developing and Deploying Converged Multimedia Services. Hrsg./Editors: Ahson, S. Verlag/Publisher: CRC Press, Erscheinungsjahr/Year: 2010. 


\section{Service Innovation for Electronic Services ${ }^{1}$}

\section{Christoph Riedl}

Technische Universität München, Boltzmannstr. 3,

85748 Garching b. München, Germany

riedlc@in.tum.de

Jan Marco Leimeister

Universität Kassel, Nora-Platiel-Str. 4,

34127 Kassel, Germany

leimeister@uni-kassel.de

\section{Helmut Krcmar}

Technische Universität München, Boltzmannstr. 3,

85748 Garching b. München, Germany

krcmar@in.tum.de

\footnotetext{
${ }^{1}$ An earlier version of this paper has been presented at the Fifteenth Americas Conference on Information Systems (AMCIS'09), San Francisco, California, 6th - 9th August 2009.
} 


\section{Table of Contents}

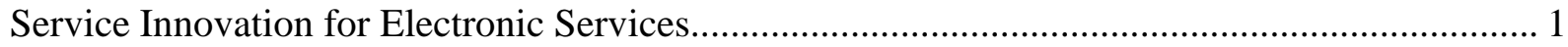

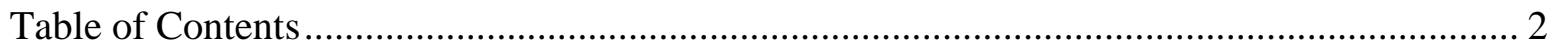

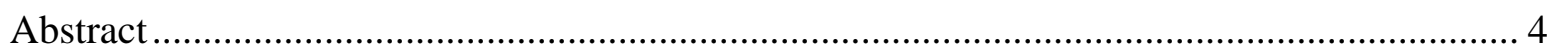

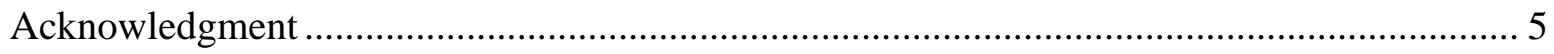

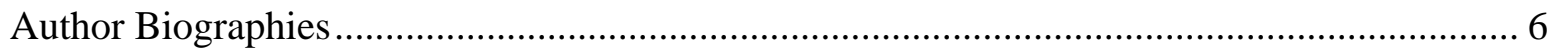

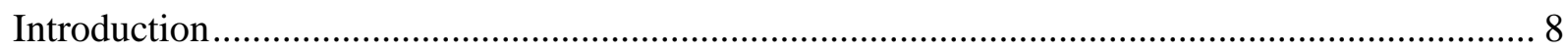

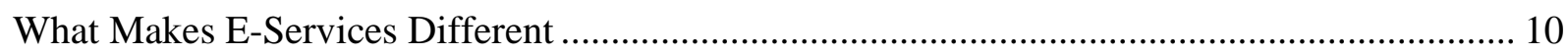

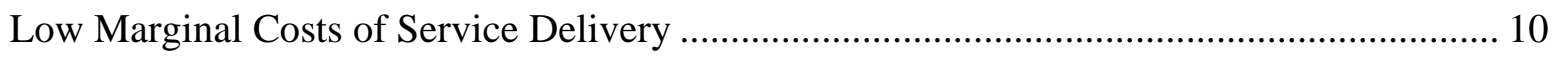

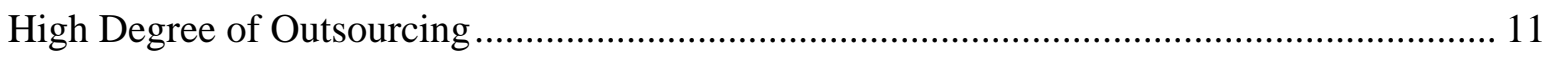

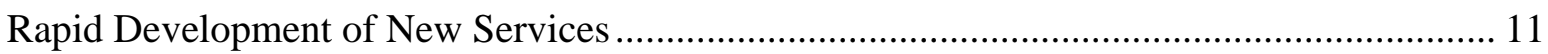

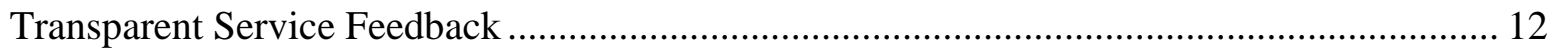

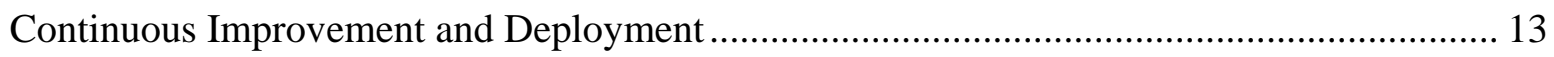

State of the Art Review of Developing Electronic Services.................................................. 14

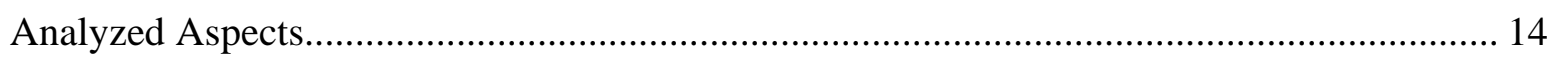

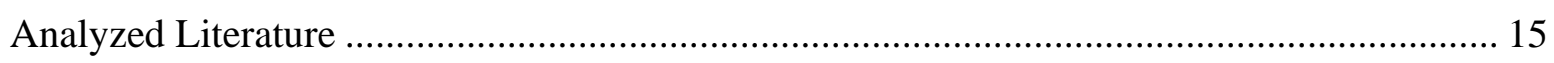

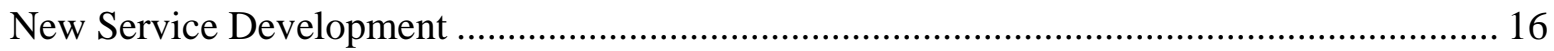

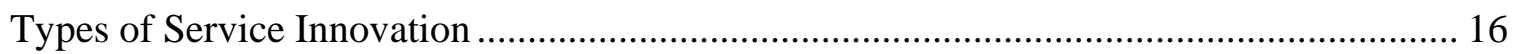

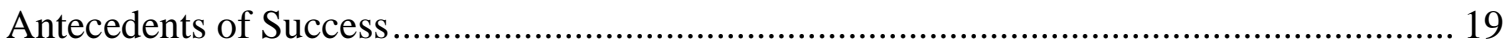

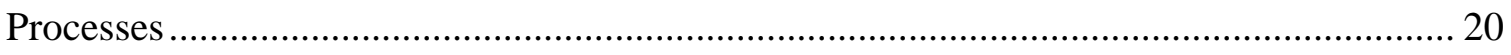




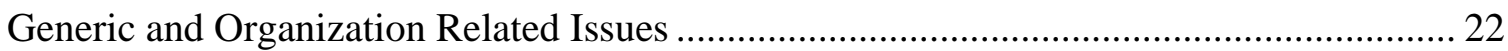

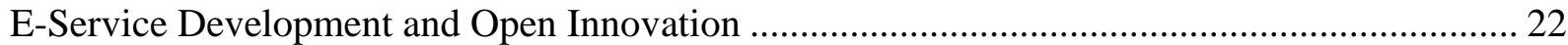

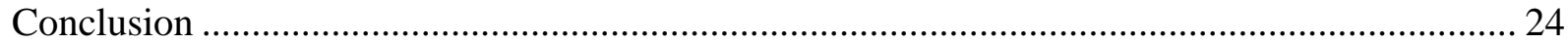

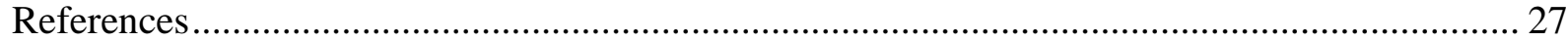




\section{Abstract}

We are on a way towards a service economy and much of our society is now driven by services. Consequently, it becomes more and more important to develop new services which is commonly referred to as New Service Development (NSD). In the general area of services, those services delivered electronically over the Internet play an increasing role. In this article we derive a set of key attributes that distinguish electronic from non-electronic services and investigate their potential influence on NSD. Using these attributes as a framework for analysis the article presents a literature review of core NSD research with regards to their applicability to the development of electronic services. This leads to the identification of problems that have to be addressed when developing electronic services but also to new possibilities that can be exploited. The analysis reveals certain gaps in NSD research. In particular, current NSD methods are not designed to address the rapidly changing nature and the networked structure of most electronic services. Moreover, these service development methods do not fully exploit the potentials and advantages offered by electronic services over their non-electronic counterparts. These are in particular potentials for continuous improvement, rapid deployment of service changes, and the transparent feedback generated by service usage.

Keywords: Service innovation, open innovation, electronic service, e-service, new service development, NSD. 


\section{Acknowledgment}

This research received funding from the German Federal Ministry of Economics and Technology (BMWi) under grant code 10MQ07024. The responsibility for the content of this publication lies with the authors. 


\section{Author Biographies}

Christoph Riedl is a research associate and $\mathrm{PhD}$ student at the Chair for Information Systems at the Department of Informatics, Technische Universitaet Muenchen (TUM). He received a BSc in computer science from TUM in 2006 and an MSc in Information Systems in 2007. He spent time studying and researching abroad at National University of Singapore (NUS) and at Queensland University of Technology (QUT). His research interests include service science, IT-enabled value webs, open and service innovation as well as Semantic Web and Web 2.0 technologies.

Prof. Dr. Jan Marco Leimeister is a full professor of Information Systems and holds the Chair for Information Systems at Kassel University. He is furthermore a research group manager at the Computer Science Department at Technische Universitaet Muenchen, Munich, Germany. He runs research groups on Virtual Communities, eHealth, Ubiquitous/Mobile Computing and manages several publicly funded research projects. His teaching and research areas include IT Innovation Management, Service Science, Ubiquitous and Mobile Computing, Collaboration Engineering, eHealth, Online Communities, and IT Management.

Prof. Dr. Helmut Krcmar is a full professor of Information Systems and holds the Chair for Information Systems at the Department of Informatics, Technische Universitaet Muenchen (TUM), Germany since 2002. He worked as Post Doctoral Fellow at the IBM Los Angeles Scientific Center, as assistant professor of Information Systems at the Leonard Stern School of Business, NYU, and at Baruch College, CUNY. From 1987 to 2002 he was Chair for Information Systems, Hohenheim University, Stuttgart. His research interests include Information and Knowledge Management, IT-enabled Value Webs, Service Management, 
Computer Supported Cooperative Work, and Information Systems in Health Care and eGovernment. 


\section{Introduction}

With an increasing importance of the service sector, the management of new service development (NSD) is becoming a key competitive concern for many companies (Menor, Tatikonda and Sampson, 2002; Johnson, Menor, Roth and Chase, 2000; Fitzsimmons and Fitzsimmons, 2000; Johne and Storey, 1998; Gallouj and Weinstein, 1997). Despite its importance it is still not a very well understood topics and ranks behind the research on new product development (Menor et al., 2002).

An increasing proportion of services are now electronic services delivered over the Internet. However, the systematic design of electronic services is not covered sufficiently in NSD literature. Yet the importance and relevance of designing electronic services is demonstrated by examples of market success of services like Google, Amazon Web-services, or Salesforce.com. Moreover, a concerted research effort to address fields like "Internet of Services" and "Service Ecosystems” is forming (Janiesch, Ruggaber and Sure, 2008; Riedl, Böhmann, Leimeister and Krcmar 2009; Riedl, Böhmann, Rosemann and Krcmar, 2009). Additional, more general approaches such as Service Oriented Architectures and cloud computing are established and thus exposing coarse-grained business components to simplify the assembly and deployment of business solutions built as networks of services (Beisiegel, Blohm, Booz et al., 2005). The purpose of this article is to derive a set of key attributes that distinguish electronic from nonelectronic services and their potential influence on NSD. These key attributes are then used as a framework for analyzing NSD literature with regards to their applicability to the development of electronic services.

To frame the object of interest a definition of electronic service is mandatory. Rust and Kannan (2003) define e-service as “the provision of service over electronic networks.” Electronic 
networks include, but are not limited to the Internet. Other electronic environments such as mobile networks, ATMs, and self-service kiosks are also included by this definition. In business science literature this usually refers to an Internet-based version of traditional services (Baida, Gordijn and Omelayenko, 2004). This includes both, services that only use the Internet as an user-interface but where actual service fulfillment might include non-electronic channels (e.g., online shopping), as well as services that are entirely delivered electronically (e.g., music download). The notion of e-services is not limited to the business-to-consumer domain but also encompasses the domains of business-to-business, government-to-public, and intraorganizational entities (Rust and Kannan, 2003). Web-service is a term used in computer science and is usually not found in business science. When used in business science, it either refers to the computer science definition or it simply refers to services delivered over the Web in the meaning of e-service (Baida et al., 2004). In a computer science context, a Web-service is defined by Haas and Brown (2004) as a "software system designed to support interoperable machine-to-machine interaction over a network.” Web-services have an interface described in a machine-processable format and other systems interact with the Web-service in the manner prescribed by its description using standardized messages.

For the purpose of this work a service will be defined as a business activity of value exchange that is accessible through an electronic interface. In that sense a service as it will be understood within the context of this work lies at the intersection of the business definition of a service (i.e., business activity of value exchange) and the technical implementation of a Web-service. Such a service is more than the pure technical implementation of a Web-service or another software implementation. The service has to implement a business activity that a user attributes value to. Yet services delivered in a non-electronic fashion, such as services offered by hospitality, are not 
within the scope of this work. An e-service following our definition may be provided through a single implementation of a Web-service or through a collection of Web-services that together form a new value added service which is thus delivered through an electronic interface.

\section{What Makes E-Services Different}

We argue that certain distinct characteristics of electronic services mandate a customized development process for these services as opposed to traditional new service development. Through an analysis of existing research related to electronic services we identified five key areas of difference: (1) the cost structure of services, (2) the high degree of outsourcing, (3) rapid development of new services, (4) the availability of transparent service feedback, and (5) the continuous improvement of services. The following sections motivate each area of difference.

\section{Low Marginal Costs of Service Delivery}

The economics of information have been recognized as dramatically different from the economics of physical items (Evans and Wurster, 2000). This leads to a unique cost structure both in comparison to physical products as well as other non-electronic services.

The typical cost structure of an information technology supplier involves high fixed costs for developing the infrastructure and applications, and very low, sometimes near zero, marginal costs for actual service provision (Whinston, Choi and Stahl, 1997; Bakos, 1998). Through the use of electronic intermediaries the search and transaction costs are further reduced (Bakos, 1998). This further reduces variable costs of service provisioning and service use. Contrary to non-electronic services that are sometimes very labor intensive (e.g., hospitality services) this difference should explicitly be addressed during service development. 


\section{High Degree of Outsourcing}

Outsourcing is a standard concept that is being considered through make or buy decisions both in manufacturing and in services. In electronic services, outsourcing plays a particularly important role. First, since service provisioning occurs in the back-office and electronic services can easily be delivered from remote locations there is no need to collocate service production with the service consumption (Miles, 2005). Traditional services do not enjoy this opportunity, e.g., through the need of attractive locations (think of a down-town café). Second, the high degree of technical standardization achieved through various Web-service standards (Champion, Ferris, Newcomer and Orchard, 2002) and efforts to standardize Service Oriented Architectures (Beisiegel et al., 2005), this high degree of outsourcing is accompanied by the necessary technical framework to make outsourcing of individual service components feasible. This is additionally fostered through the increased availability of high-speed networks and current developments in cloud computing (Böhm, Leimeister, Riedl and Krcmar, 2009). The technical standardization allows the easy integration of other providers' components and services can be provided in a network of actors combining many service components (e.g., travel services integrating flight, hotel, local transportation, and other reservation services). Once these services are integrated through the development of appropriate interfaces infinite re-use of existing components with no further integration or assembly costs is possible. However, this can lead to complex value networks with different actors working together in a federated service environment. This leads to complex value constellation in distributed networks which are harder to manage with the increased number of involved actors (Vanhaverbeke and Cloodt, 2006).

\section{Rapid Development of New Services}

A differentiation strategy is difficult to attain as services can be copied easily and are not 
applicable to patent protection (Porter, 2001; Hipp and Grupp 2005). Consequently, only continuous innovation can lead to economic success. However, these effects common to all service areas are magnified in the area of electronic services. Advances in electronic services are particularly rapid and low barriers of entry have been attributed to electronic services (cf., Porter, 2001; Menor et al., 2002; Evans and Wurster, 2000). This rapid development is further fueled by extremely fast technological progress and fast emerging of technologies. This fast technological progress not only creates opportunities for new service concepts but also affects customers expectations and preferences which require constant innovations to meet them (e.g., all the electronic services offered on the Apple iPhone store which was only just created through the advances in mobile phone technology). Furthermore, the very nature of electronic services benefits radical innovation through major innovations and start-up businesses (Menor et al., 2002; Johnson et al., 2000).

\section{Transparent Service Feedback}

Through the electronic nature of service delivery the interaction between a service consumer and the service itself becomes very transparent. A simple example of this effect is the monitoring of click-through-rates in online shops. This generates a nearly complete picture of customer interactions which a traditional shopping mall operator would dream of. This creates various opportunities for service design and innovation. Interactions between users and the service can be recorded and replayed. Thus, a service itself can gather information about what else users might want or need (Riedl, Böhmann, Rosemann and Krcmar, 2008). The transparent nature of service feedback is also an option for new business models based on new licensing concepts. As the usage information is transparent to providers billing is not only possible based on the actual use but on the value generated for the customer. For example, 
instead of charging for a Customer Relationship Management (CRM) service based on concurrent users, charging based on the actual revenue generated through the CRM service would be possible.

\section{Continuous Improvement and Deployment}

Unlike software being sold over the counter electronic services are no longer restricted to a scheduled release cycle where changes, improvements, and bug fixes require months to be integrated into the service (termed “perpetual beta” by some authors, cf. O’Reilly, 2007; Morris, 2006). Rather, services are developed in the open with tight integration of service users or even by the users themselves. For example, Google services like search and many of the online applications are constantly updated. There are no distinct releases with version numbers assigned to the service instance currently offered. Rather, improvements slip into the market almost unnoticed. The innovation process is full of small cycles that allow a service to be improved almost instantly. Additionally, as services are delivered through a global delivery system, there are no local differences in the services offered and the new version is instantly available to all users. This would be very hard to implement for non-electronic services where physical facilities would need to be upgraded and personnel to be trained.

This has two fundamental effects on the development of new electronic services. First, the benefits of perpetual beta and continuously improvements can be used to upgrade services with the improvements instantly visible to all users. Second, service providers have to make sure that improvements are visible to users and are valued as such. 


\section{State of the Art Review of Developing Electronic Services}

\section{Analyzed Aspects}

Based on the key differences between electronic and non-electronic services elaborated above and their impact on the new service development process, we developed an analysis framework. This framework has been used to review existing literature on their suitability for guiding the development of new electronic services. The following list presents our analysis framework.

- Are there defined methods and processes to guide the development of new services?

- Are electronic services explicitly covered by the method?

- Are all phases of the innovation process included in the method or just selected aspects such as idea generation or implementation?

- Does the approach pay special attention to the IT service specific cost structure?

- Is a high degree of outsourcing and modularization supported?

- Does the method provide support for very fast cycles and immediate deployment?

- Does the method integrate aspects of continuous improvement through transparent feedback?

- Does the method includes a step to look for existing components to re-use to take advantage of low search costs and standardization to shorten time to market and reduce fixed costs?

- Is special attention paid to complex value constellation in distributed networks (based on outsourcing)?

The following sections will review the literature in the area of new service development with regards to their prescriptive support for designing and developing services. Special attention will be paid to those aspects distilled above that are unique to electronic services compared to non- 
electronic services.

\section{Analyzed Literature}

A systematic literature review has been performed. An initial search using the key words "new service development” or “NSD” on online databases ScienceDirect and EBSCOhost has been performed to cover a broad range of high-quality, peer reviewed publications. The review time period was from 1997 to 2008 as NSD research received significant attention during this time (Zhou and Tan, 2008). The initial search returned over 300 articles. Accounting for duplicate results and after a preliminary scan of the article's abstracts the number of articles to be included could be substantially reduced. Reasons for excluding articles where, among others, a different understanding of e-service that related more to information system adoption or articles that refer to NSD literature or use NSD methods but do not contribute to extend NSD research itself. Moreover, several cross-referenced articles and books not found in those databases have been included and further extended by a comprehensive review of relevant academic journals that we expected to have published articles on NSD. Finally, 42 relevant journal and conference articles as well as books and book chapters have been included in the review. The literature on NSD focuses mainly on success factors and the development of (process) models (Zhou and Tan, 2008) as well as a large set of summary and review based articles. The topics covered in the analysis and the number of articles that predominantly deal with this topic are shown in Table 1 . A similar distribution of main themes covered in NSD research has also been reported by Zhou and Tan (2008). Table 2 gives an overview over the publications by year.

Table 1 Overview of topics covered in the analyzed articles

\begin{tabular}{|l|l|}
\hline NSD Research Theme & Frequency \\
\hline Types of innovation & 10 \\
\hline
\end{tabular}




\begin{tabular}{|l|l|}
\hline Antecedents / success factors & 10 \\
\hline Process models / methods & 13 \\
\hline Generic (literature reviews) & 9 \\
\hline
\end{tabular}

Table 2 Publications by year

\begin{tabular}{|l|l|l|l|}
\hline Year & Frequency & Year & Frequency \\
\hline 1997 & 4 & 2003 & 5 \\
\hline 1998 & 2 & 2004 & 2 \\
\hline 1999 & 0 & 2005 & 4 \\
\hline 2000 & 10 & 2006 & 3 \\
\hline 2001 & 1 & 2007 & 4 \\
\hline 2002 & 3 & 2008 & 4 \\
\hline
\end{tabular}

\section{New Service Development}

NSD involves the development of service offerings such as financial services, health care, telecommunications services, leisure and hospitality services, information services, legal and educational services as well as many more (Johne and Storey, 1998). Contrary to new product development (NPD) which is regarded as a base for much research in this area, new service development stresses core differences between products and services: intangibility, heterogeneity, simultaneity (Fitzsimmons and Fitzsimmons, 2001). Despite a growing body of knowledge our understanding of new services development processes for especially electronic services is still limited (Menor et al., 2002).

Types of Service Innovation

A first set of articles tries to bring structure to the types of innovations found in services by 
proposing typologies of service innovation. Edvardsson and Olson (1996) suggest that service innovation includes the development of (1) a service concept (what customer needs are satisfied), (2) a service system (the resources necessary to deliver a service), and (3) a service process. These three areas make service innovation a complex and multidimensional undertaking (Essen and Conrick, 2008). Johnson et al. (2000) suggest six categories to structure service innovation (Table 3).

Table 3 A typology of new services (adapted from Johnson et al. 2000)

\begin{tabular}{|l|l|}
\hline New Service Category & \\
\hline Radical innovations & New services for markets as yet undefined; innovations usually \\
\hline Major innovation & Nriven by information and computer-based technologies \\
\hline Start-up business & services \\
\hline presently served & New service offerings to existing customers of an organization \\
(although the services may be available from other companies)
\end{tabular}


Other types of service innovation noted are, for example, the new combinations of existing services or the combination of customer coproduction with new service characteristics or competencies (Aa and Elfring, 2002; Gallouj and Weinstein, 1997). Hipp and Grupp (2005) identified four patterns of key factors influencing service innovation: knowledge intensity, network basis, scale intensity, and supplier dominance. Especially the network-based innovations seem to match most electronic services due to their reliance on technological systems for information and communication processing. Menor et al. (2002), moreover, argue that the nature of electronic services especially benefit radical innovations (major innovation and start-up business).

Barras (1990) argued that IT-based service innovation follows a pattern that is different from that found in manufacturing. He claims that in the early life cycle phase of a service "technology push” is the main driving force whereas in the later phases incremental process innovation through “demand pull” is the driving force. In the latter phase pressures by users increasingly force service providers to differentiate themselves leading to differentiated products and product innovation. To account for this fact and the specifics of service industries, Barras proposed a reverse product life cycle (RPC) model for services. The reverse product life cycle model suggests that innovation takes place in three phases: improved efficiency, improved quality, and new services phase (Barras, 1990). Other articles also discuss the specific influence of IT innovations on service innovation. Especially the process innovation aspects achieved through the use of IT in back-end service provisioning and automation potentials are notable (Miles, 2005). However, these types of innovation are not specific to e-services as IT is a technology to be applied to the generic information-processing activities of services (Miles, 2005). He concludes that a study of IT's influence does not reveal much about the dynamics and processes 
of innovation.

None of the studies cited above explicitly addresses electronic services but are taken from diverse industries. However, there is an established hypothesis that innovation patterns in services are less sector-dependent, and that every type of innovate can be found within each individual service industry. In particular, there is no specific industry to offer electronic services per se. Moreover, knowledge insensitivity does not necessarily imply that the service is delivered electronically. For example, many financial services, though highly IT-based, are not electronic. Yet an electronic ticket reservation service offered by an airline is. As Miles (2005) notes "some online information services originated form in-house data management services, e.g. from publishing firms.”

\section{Antecedents of Success}

Related to the different types of innovation a substantial part of the literature addresses the question what antecedents of NSD success are (de Jong and Vermeulen, 2003). Generic antecedents include strategic fit, skilled front-line employees, high involvement teams, clear project structure, formal processes, top management support, and product champions (de Brentani, 2001; Vermeulen and van der Aa, 2003; de Jong and Vermeulen, 2003). Stevens and Dimitriadis (2005) report that NSD is especially successful when learning has been achieved during the development process. Furthermore, two evolutionary stages of “manage key activities” and “create a climate for continuous innovation” have been identified (de Jong and Vermeulen, 2003). In an analysis of the antecedents of NSD success, IT systems and process structure have been found to have a positive impact on speed of NSD (Froehle, Roth, Chase and Voss, 2000). None of the studies explicitly addressed electronic services. It can be assumed that these antecedents are generic enough to play an important role for electronic services as well, but 
specific aspects of e-services have not been studied so fare. In an analysis of the antecedents of NSD success, IT systems and process structure have been shown to have a positive impact on speed of NSD process (Froehle et al., 2000). As NSD speed is of particular importance for eservices, this is a valuable contribution. A notable exception is Menor et al. (2002) who did not study e-service antecedents of success but propose that the aspect of external newness is especially salient as electronic services are often replications of services already known to customers but that are now offered in an electronic way.

\section{Processes}

With regards to traditional services NSD can be seen as a rather complete method covering all phases of the service life cycle. There are in particular a wide set of process models defined for the development of new services. In a comparative study of existing NSD literature Johnson and Menor (1997) proposed a basic model of four phases: design, analysis, development, and launch. Though models included in the literature review did not match precisely and different phases were more detailed in some models and more succinct in others, these four phases where found in all.

More recently, Johnson et al. developed a new NSD process based on four broad stages and 13 detail tasks to produce and launch a new service (Johnson et al., 2000). The model emphasizes the nonlinearity of the NSD process through a continuous cycle as well as the importance of enabling factors: teams, tools, and organizational culture (see Figure 1).

Figure 1 NSD process cycle (source: adapted from Johnson et al., 2000).

On a very generic level Bessant and Davies (2007) suggest that organizations have to manage 
four phases in the innovation process: search and scan their environment to pick up signals for potential innovation, strategically select those ideas that the organization will commit resources to, implement the innovation, and finally reflect on the previous phases to achieve organizational learning.

An issue also commonly addressed in NSD is “design for delivery” (Bullinger, Fähnrich and Meiren, 2003). As many services are highly labor intensive (e.g., hospitality services) the motivation to optimize new services for efficient delivery is high. As electronic services follow a reversed cost structure these approaches are not suitable for e-service development.

Another common distinction in service development is that between a "front-office" and "backoffice” (e.g., Metters and Vargas, 2000). Yet, sole focus on "back-office” operational efficiency is not enough and has been neglected with many e-services. As argued by Riedl et al. (2008) perceived quality measures have to be taken into account to address satisfaction issues commonly addressed in "front-office” design. Moreover, Johnson et al. (2000) note that different NSD processes are necessary for different types of innovation. In particular they identify incremental service innovations, radical service innovations, and technology-driven services as key differences that should be used to choose the appropriate NSD process and propose this as an avenue for future research. With regards to the perpetual beta aspect of electronic services, this result might be useful in guiding the selection of a specific process that is designed especially for incremental innovations (de Brentani, 2001).

Froehle and Roth (2007) propose a framework for new service development that integrates both process- and resource-oriented approaches. The resource-oriented practices focus on cultivating and developing the intellectual, organizational, and physical resources that support NSD capabilities. The process-oriented practices focus on planning, defining, and executing the actual 
stages of the service development (see Figure 2). Their belief and motivation for this integrated view is that both resource and process capabilities are required for successful service development.

Figure 2 The Resource-Process framework of new service development (source: adapted from Froehle and Roth, 2007).

Pavitt (2005) acknowledges the fact that services have to be continuously improved and a continuous mapping of service artifacts to market needs and demands is necessary. However, there is no consideration for the vast transparent feedback available in e-services and the very fast cycle times.

Generic and Organization Related Issues

Syson and Perks (2004) address network issues in NSD. They conclude that interactions are critical for NSD and that the incorporation of disparate perspectives is beneficial (i.e., they increase creative potential) and that the network perspective helps incorporate relevant resources and actors. However, the very nature of services (intangibility, heterogeneity and inseparability) brings considerable complexities to the exchange processes of NSD. As services are copied easily the development of a network approach to NSD could provide firms with a source of competitive advantage. They do not, however, address the management of the resulting complex value networks.

\section{E-Service Development and Open Innovation}

How can innovations be developed in open, networked, and dynamic systems and markets such as those most electronic services are found in? Outside the core area of New Service 
Development a new research stream called open innovation is making progress (Chesbrough, 2003). The tools and methods proposed by open innovation seem to address the problems that are encountered when developing electronic services (e.g., fast development) and might also help to exploit the new opportunities (e.g., transparent feedback).

Three core process archetypes in open innovation have been identified: the outside-in process, the inside-out process, and the coupled process (Gassmann and Enkel, 2004). The outside-in process enriches a company's knowledge and innovation base through the integration of external knowledge sources, particularly the knowledge sources of customers and suppliers, to increase its innovativeness. The inside-out process exploits a company's unused inventions in different markets and a managed trade of intellectual property, e.g., through licensing. The coupled process is a combination of both the outside-in and the inside-out processes intended to maximize the benefits of both approaches.

These three archetypes are achieved through various means of perspectives on opening the innovation and development including: (1) globalization of innovation, (2) outsourcing of R\&D, (3) early supplier integration, (4) user innovation, and (5) external commercialization of innovations (Gassmann, 2006). These open innovation processes lead to interfirm cooperation and development of ecosystems of networked firms sharing technology and trading intellectual property (West, Vanhaverbeke, and Chesbrough, 2006; Stathel et al., 2008). The benefits of customer integration, user driven innovation and open innovation are well recognized and established in research (e.g., von Hippel, 2005; Ogawa and Piller, 2006; Lakhani and Panetta, 2007; West and Lakhani, 2008; Surowiecki, 2005; Chesbrough, 2006; Gassmann, 2006). However, these results have not yet been linked to NSD and thus escaped the systematic literature review. 
This research argues that an open innovation paradigm rather than a closed innovation paradigm is necessary for successful innovation of electronic services. This is due to their heavy reliance on re-use, their reliance on new business models, and knowledge leveraging as services are implemented as software (Gassmann 2006). As open innovation is geared towards systematically integrating external ideas and influences into the internal innovation process, a systematic approach becomes available for the integration of the transparent feedback generated by service usage of electronic services.

To support such an open innovation process in the networked environment in which electronic services operate it would be necessary to provide a central, shared innovation repository through which the diverse actors like service provider, customer, and aggregator can interact (Riedl et al. 2009a). Thus, a duality of an open and networked structure for the delivery of many electronic services and an open and networked model for the development of these services is created. Taken together the special requirements posed by developing new electronic services, the environment of highly networked services, and the move to an open innovation model offer the potential for new and improved service innovation approaches that are until now little understood.

\section{Conclusion}

NSD is a rather complete method describing key processes and tasks. Moreover, it covers all phases of the life cycle from design, analysis, and development to launch as is apparent from the wide collection of process models that have been reported. Especially noteworthy is the cyclic model of Johnson et al. (2000). However, the design of electronic services is not explicitly covered except in articles offering basic definitions of e-services. A notable exception is only the article by Menor et al. (2002) that also shows gaps that exist and points to research challenges. 
While several research results exist that can point in the direction of successful development of new e-services, there are certain gaps in NSD research with regards to key attributes of electronic services and their influence on NSD. In particular current NSD methods are not well equipped to address the rapid nature and specific cost structure found in electronic services. Moreover, current NSD methods are not well suited to fully exploit the various advantages offered by electronic services over non-electronic services. These are in particular the transparent feedback generated by service usage and potentials for continuous improvement and rapid deployment of service changes.

This research only focuses on core NSD literature. However, there are other streams of research that might be suitable to target some of the key issues. We propose in particular that an open innovation process should be taken towards the development of new electronic services. Future research should address how the research gaps identified in this analysis of NSD literature can be addressed by other streams of research and how open innovation could be specifically used for innovation of electronic services. To address the potentials of increased outsourcing and also increase the speed of development NSD processes for electronic services could also be extended to include a specific step of searching for existing service components that can be re-used. Literature on mash-ups could serve as initial guidance in this area. Furthermore, there are potentials of participatory development of new e-services and open innovation (e.g., Riedl et al. 2009a; Leimeister, Huber, Bretschneider and Krcmar, 2009) that could provide useful for fast and successful development of new services.

In summary, the research on electronic services in general and the development of these services in particular is, despite their increasing importance, still very limited. This research provides an initial basis in elaborating on the key aspects that distinguish non-electronic from electronic 
services and points to gaps in the literature that could be addressed by future research. 


\section{References}

van der Aa, W. and Elfring, T. 2002. Realizing innovation in services. Scandinavian Journal of Management 18(2):155-171.

Baida, Z., Gordijn, J. and Omelayenko, B. 2004. A shared service terminology for online service provisioning. In Proceedings of the 6th international conference on electronic commerce (ICEC '04), ACM Press, 1-10.

Bakos, Y. 1998. The emerging role of electronic marketplaces on the Internet. Communications of the ACM 41(8):35-42.

Barras, R. 1990. Interactive innovation in financial and business services: the vanguard of the service revolution. Research Policy 19(3):215-37.

Beisiegel, M., Blohm, H., Booz, D., et al. 2005. Building Systems using a Service Oriented Architecture. Whitepaper, SCA Consortium.

Bessant, J. and Davies, A. 2007. Managing service innovation. In Innovation in Services - DTI Occasional paper no. 9, ed. Bessant, J., Davies, A., Tether, B., Howells, J., Voss, C., Zomerdijk, L. and Massini, S., 61-95. UK: Department of Trade and Industry. de Brentani, U. 2001. Innovative versus incremental new business services: different keys for achieving success. Journal of Product Innovation Management 18(3):169-187.

Böhm, M., Leimeister, S., Riedl, C. and Krcmar, H. 2009. Cloud Computing - Outsourcing 2.0 or a new Business Model for IT Provisioning? In Application Management, ed. Keuper, F., Oecking, C. and Degenhardt, A. Wiesbaden: Gabler.

Bullinger, H., Fähnrich, K. and Meiren, T. 2003. Service engineering - methodical development of new service products. International Journal of Production Economics 85(3):275-287.

Champion, M., Ferris, C., Newcomer, E. and Orchard, D. 2002. Web Services Architecture, 
W3C Working Draft 14 November 2002, http://www.w3.org/TR/2002/WD-ws-arch-20021114/ (accessed November 1, 2009).

Chesbrough, H. 2003. The era of open innovation. MIT Sloan Management Review 44(3):35-41. Chesbrough, H. 2006. Open Innovation: The New Imperative for Creating and Profiting from Technology. Boston: Harvard Business School Press.

Edvardsson, B. and Olsson, J. 1996. Key concepts for new service development. Service Industry Journal 16(2):140-164.

Essen, A. and Conrick, M. 2008. New e-service development in the homecare sector: Beyond implementing a radical technology. International Journal of Medical Informatics 77:679-688. Evans, P. and Wurster, T. 2000. Blown to Bits: How the New Economics of Information Transforms Strategy. Boston: Harvard Business School Press.

Fitzsimmons, J. and Fitzsimmons, M. 2000. New Service Development: Creating Memorable Experiences. Thousand Oaks: Sage Publications.

Fitzsimmons, J. and Fitzsimmons, M. 2006. Service management: operations, strategy, and information technology. New York: McGraw-Hill.

Froehle, C. and Roth, A. 2007. A Resource-Process Framework of New Service Development. Production and Operations Management 16(2):169-188.

Froehle, C., Roth, A., Chase, R. and Voss, C. 2000. Antecedents of New Service Development Effectiveness: An Exploratory Examination of Strategic Operations Choices. Journal of Service Research 3(1):3-17.

Gallouj, F. and Weinstein, O. 1997. Innovation in services. Research Policy 26(4):537-556.

Gassmann, O. 2006. Opening up the innovation process: towards an agenda. R\&D Management 36(3):223-228. 
Gassmann, O. and Enkel, E. 2004). Towards a Theory of Open Innovation: Three Core Process Archetypes. In Proceedings of the R\&D Management Conference (RADMA). Sessimbra, Portugal July, 8-9.

Haas, H. and Brown, A. 2004. Web Services Glossary. W3C Working Group Note 11 February 2004, http://www.w3.org/TR/ws-gloss/ (accessed November 1, 2009).

von Hippel, E. 2005. Democratizing Innovation. Cambridge: MIT Press.

Hipp, C. and Grupp, H. 2005. Innovation in the service sector: The demand for service-specific innovation measurement concepts and typologies. Research Policy 34(4):517-535.

Janiesch, C., Ruggaber, R. and Sure, Y. 2008. Eine Infrastruktur für das Internet der Dienste. HMD 261:71-79 (in German).

de Jong, J. and Vermeulen, P. 2003. Organizing successful new service development: a literature review. Management Decision 41(9):844-858.

Johne, A. and Storey, C. 1998. New service development: a review of the literature and annotated bibliography. European Journal of Marketing 32(3/4):184-251.

Johnson, S. and Menor, L. 1997. Integrating service design and delivery: A proposed model of the new service development process, paper presented at the annual meeting of the Decision Sciences Institute, San Diego, cited after: Johnson, S., Menor, L., Roth, A. and Chase, R. 2000 A Critical Evaluation of the New Service Development Process: Integrating Service Innovation and Service Design. In New Service Development: Creating Memorable Experiences, ed.

Fitzsimmons, J. and Fitzsimmons, M., 1-32. Thousand Oaks: Sage Publications.

Johnson, S., Menor, L., Roth, A. and Chase, R. 2000. A Critical Evaluation of the New Service Development Process: Integrating Service Innovation and Service Design. In New Service Development: Creating Memorable Experiences, ed. Fitzsimmons, J. and Fitzsimmons, M., 1-32. 
Thousand Oaks: Sage Publications.

Lakhani, K. and Panetta, J. 2007. The Principles of Distributed Innovation. Innovations:

Technology, Governance, Globalization 2(3):97-112.

Leimeister, J. M., Huber, M., Bretschneider, U. and Krcmar, H. 2009. Leveraging

Crowdsourcing - Theory-driven Design, Implementation and Evaluation of Activation-

Supporting Components for IT-based Idea Competitions. Journal of Management Information

Systems 26(1):197-224.

Menor, L., Tatikonda, M. and Sampson, S. 2002. New service development: areas for

exploitation and exploration. Journal of Operations Management 20(2):135-157.

Metters, R. and Vargas, V. 2000. A typology of de-coupling strategies in mixed services. Journal of Operations Management 18(6):663-682.

Miles, I. 2005. Innovation in Services. In The Oxford Handbook of Innovation, ed. Fagerberg, J.,Nelson, R. and Mowery, D., 433-458. New York: Oxford University Press.

Morris, J. 2006. Software Product Management and the Endless Beta, http://jimmorris.blogspot.com/2006_08_01_jimmorris_archive.html, 2006-08-30, (accessed November 01, 2009).

Ogawa, S. and Piller, F. 2006. Reducing the Risks of New Product Development. MIT Sloan Management Review 47(2):65-71.

Pavitt, K. 2005. Innovation Processes. In The Oxford Handbook of Innovation, ed. Fagerberg, J., Nelson, R. and Mowery, D., 86-114. New York: Oxford University Press.

O'Reilly, T. 2007. What is Web 2.0: Design Patterns and Business Models for the Next Generation of Software. Communications \& Strategies First Quarter 2007:17-37.

Riedl, C., Böhmann, T., Rosemann, M. and Krcmar, H. 2008. Quality Aspects in Service 
Ecosystems: Areas for Exploitation and Exploration. In Proceedings of International Conference on Electronic Commerce (ICEC '08), ACM Press, 1-7.

Riedl, C., Böhmann, T., Leimeister, J. M. and Krcmar, H. 2009a. A Framework for Analysing Service Ecosystem Capabilities to Innovate. In Proceedings of 17th European Conference on Information Systems (ECIS'09).

Riedl, C., Böhmann, T., Rosemann, M. and Krcmar, H. 2009b. Quality Management in Service Ecosystems. Information Systems and e-Business Management 7(2):199-221.

Rust, R. T. and Kannan, P. 2003. E-service: A new paradigm for business in the electronic environment. Communications of the ACM 46(6):36-42.

Stevens, E. and Dimitriadis, S. 2005. Managing the new service development process: towards a systemic model. European Journal of Marketing 39(1):175-198.

Stathel, S., Finzen, J., Riedl, C. and May, N. 2008. Service Innovation in Business Value Networks. In Proceedings of XVIII International RESER Conference. Stuttgart.

Surowiecki, J. (2005). The wisdom of crowds: why the many are smarter than the few. London: Abacus.

Syson, F. and Perks, H. 2004. New service development: a network perspective. Journal of Services Marketing 18(4):255-266.

Porter, M. E. 2001. Strategy and the Internet. Harvard Business Review 79(3):62-78. Vanhaverbeke, W. and Cloodt, M. 2006. Open Innovation in Value Networks. In Open innovation: researching a new paradigm, ed. Chesbrough, H., Vanhaverbeke, W. and West, J., 258-281. New York: Oxford University Press.

Vermeulen, P. and van der Aa, W. 2003. Organizing Innovation in Services. In Service Innovation, ed. Tidd, J. and Hull, F. M., 35-53. London: Imperial College Press. 
West, J. and Lakhani, K. 2008. Getting Clear About Communities in Open Innovation. Industry and Innovation 5(2):223-231.

West, J., Vanhaverbeke, W. and Chesbrough, H. 2006. Open innovation: A Research Agenda. In Open Innovation: Researching a new Paradigm, ed. Chesbrough, H., Vanhaverbeke, W. and West, J., 285-307. Oxford: Oxford University Press.

Whinston, A., Choi, S. and Stahl, D. 1997. The Economics of Electronic Commerce.

Indianapolis: Macmillan Technical Publishing.

Zhou,Q. and Tan, K. C. 2008. A Bibliographic Analysis of the Literature on New Service

Development. In Proceedings of the International Conference on Management of Innovation and Technology (ICMIT’08), IEEE, 872-877. 